\title{
Effects of Liquid Viscosity on Agricultural Nozzle Droplet Parameters
}

\author{
Long Zhang1, Shuran Song1,2,3,4*, Daozong Sun ${ }^{1,3,4}$, Xiuyun Xue ${ }^{1,2,4}$, Qiufang Dai ${ }^{1,2,4}$, Zhen Li ${ }^{1,2,3,4}$ \\ ${ }^{1}$ College of Electronic Engineering, South China Agricultural University, Guangzhou, China \\ ${ }^{2}$ Division of Citrus Machinery, China Agriculture Research System, Guangzhou, China \\ ${ }^{3}$ Guangdong Engineering Research Center for Monitoring Agricultural Information, Guangzhou, China \\ ${ }^{4}$ Guangdong Engineering Technology Research Center for Mountainous Orchard Machinery, Guangzhou, China \\ Email: *songshuran@scau.edu.cn
}

How to cite this paper: Zhang, L., Song, S.R., Sun, D.Z., Xue, X.Y., Dai, Q.F. and Li, Z. (2019) Effects of Liquid Viscosity on Agricultural Nozzle Droplet Parameters. Agricultural Sciences, 10, 1217-1239. https://doi.org/10.4236/as.2019.109091

Received: September 7, 2019

Accepted: September 23, 2019

Published: September 26, 2019

Copyright (C) 2019 by author(s) and Scientific Research Publishing Inc. This work is licensed under the Creative Commons Attribution International License (CC BY 4.0).

http://creativecommons.org/licenses/by/4.0/ cc) (i)

\begin{abstract}
To discuss the effects of pesticide viscosity on the atomisation characteristics of an agricultural nozzle, glycerite with different mass fractions was prepared to replace the pesticide. First, the atomisation region of the nozzle was meshed and sized. Second, the speed and kinetic energy of the droplets at different positions in the atomisation region were measured by Phase Doppler Anemometry. The results demonstrated that the Sauter mean diameter, volume mean diameter and arithmetic mean diameter of droplets first decreased and then increased gradually in the axial direction of the atomisation region. Surface waves of a certain pattern were formed on the liquid surface, which was ejected by the disturbance of external air resistance. As the distance increased, the amplitude increased and the wave crest was broken into small droplets. These droplets then collided and agglomerated into large droplets under the effect of gravity. Droplets had an approximately symmetric distribution on the radial direction of the atomisation region, and the droplets were small in the middle and large at the two ends. The droplet size was positively related to the radial distance. Compared with the droplet speed at the two ends, the droplet speed at the axis was higher and the droplet size was smaller. Moreover, the kinetic energy of the droplets along the axial direction decreased sharply and then increased slowly. Droplets with high viscosity at the near end of the nozzle had small kinetic energy, and the effects of liquid viscosity on the atomisation characteristics of a nozzle could not be neglected. The droplet kinetic energy slightly increased at the far end.
\end{abstract}

\section{Keywords}

Viscosity, Atomisation, Droplet Spectrum, Droplet Size, Droplet Kinetic Energy 


\section{Introduction}

One major standard of high-efficiency pesticide application technology is that pesticide deposition on the target is far higher than that for other target objects or regions. This increased deposition increases the utilisation of pesticides to a maximum extent and is an important way to eliminate damages of pesticides on operators and relieve environmental pollution [1] [2] [3]. Nowadays, China mainly depends on the mechanical spraying of pesticides. Because of the backward machinery and poor scientific application techniques, the utilisation of pesticides is only about $30 \%$. Consequently, pesticides are underused and cause serious pollution to the ecological environment, leading to pesticide residue in crops exceeding safety guidelines [4] [5].

Pesticide atomisation is a process where pesticide disperses into the atmosphere as droplets to form a mist dispersion system. This method realises significant amplification of a specific surface of atomised droplets under external forces [6] [7] [8]. A nozzle is needed to transfer the pesticide to the target plant [9]. The atomisation degree of the pesticide directly influences the drift distance and effective deposition utilisation. The atomised droplet size distribution is the main detection index of the atomisation degree of pesticide [10] [11]. Large droplets can maintain momentum over a long period, and they arrive at the target quickly, accompanied by small drift. However, excessive large droplets can easily decrease the coverage of the pesticide and cause poor target adhesiveness and pesticide loss [12] [13] [14]. In contrast, small droplets with small mass are greatly affected by air resistance and have inadequate momentum to reach the target [15]. However, small droplets help increase pesticide coverage, droplet coverage uniformity and liquid penetrability of the crop canopy [16] [17] [18] [19].

The spraying quality of the nozzle is directly related to the droplet diameter [20] [21] [22] [23]. If the chosen droplet size is appropriate, the minimum pesticide quantity shall be used to realise maximum control of plant diseases and insect pests at minimum environmental pollution cost. If the actual droplet is larger than the required droplet, the wasted pesticide may increase the cubic rate of the droplet diameter [24].

Liquid viscosity influences the atomisation performance of the nozzle [25] [26] [27] [28]. In the present study, the atomised liquid viscosity effect on the droplet size of the agricultural nozzle was studied by preparing different viscosities of droplet liquid solution. Research results provide theoretical support and experimental references to improve pesticide spraying technological and mechanical performances.

\section{Test Materials and Method}

\subsection{Test Materials}

There are dozens of pesticides for citrus pest control. Because of the multiple va- 
rieties of pesticides, it is impossible to make independent studies on each type of pesticide. In the present study, common miscible oil, wettable powder, suspending agent and water-dispersible granule were chosen as the research objects. Specifically, the following four types of pesticides were prepared according to instructions and then examined: pyridaben, imidacloprid, spirodiclofen and acetamiprid. The viscosities of the four liquids were tested by a viscometer, thus obtaining viscosity ranges of liquid under different ratios. Consequently, spraying solutions were prepared using water and glycerinum to replace the pesticide in abundant atomisation experimental studies. This preparation can avoid environmental pollution caused by pesticide experiments.

Glycerinum is a type of sticky and in-toxic liquid, and it can mix with water at any proportions. In the present study, different viscosities of spraying solutions were prepared using glycerinum and water for a contrast analysis.

In the experiment, the solid cone nozzle of the Dongguan Shaou Spraying System Co., Ltd. was applied. The diameter of the nozzle was $0.8 \mathrm{~mm}$ and its internal structure is shown in Figure 1. This nozzle is a pressure centrifugal type. Under liquid pressure, the spraying solution enters the rotating chamber through two liquid phases, rotates and is then ejected by the nozzle.

\subsection{Experimental Apparatus}

In the present study, the main experimental apparatus included: 1) Phase Doppler Anemometry (PDA) from DANTEC Company (Denmark) that has a particle measuring range of $1-10,000 \mu \mathrm{m}$ and a measuring error of $1 \%$; 2) NDJ-8T digital rotating viscosity meter from Shanghai Fangrui Instrument Co., Ltd., which has a measuring range of $1-2$ million, measuring error of $\pm 1 \%$ and a repetitive error of $\pm 0.5 \%$. All instruments meet the measurement requirements of relevant parameters.

\subsection{Test Platform}

The test platform of the droplet parameters of the nozzle is shown in Figure 2.

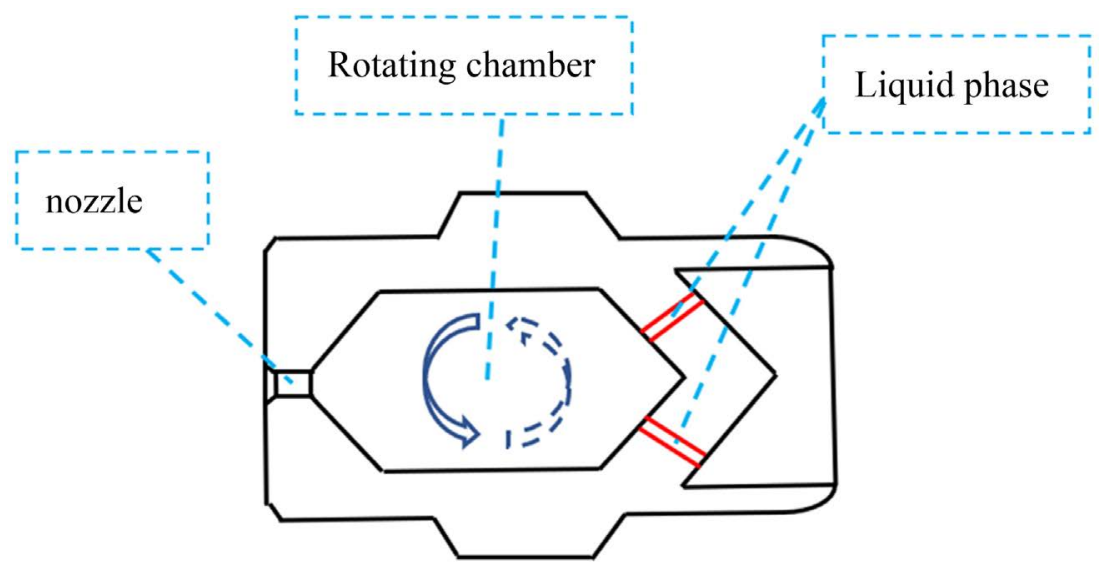

Figure 1. Internal structure of the nozzle. 


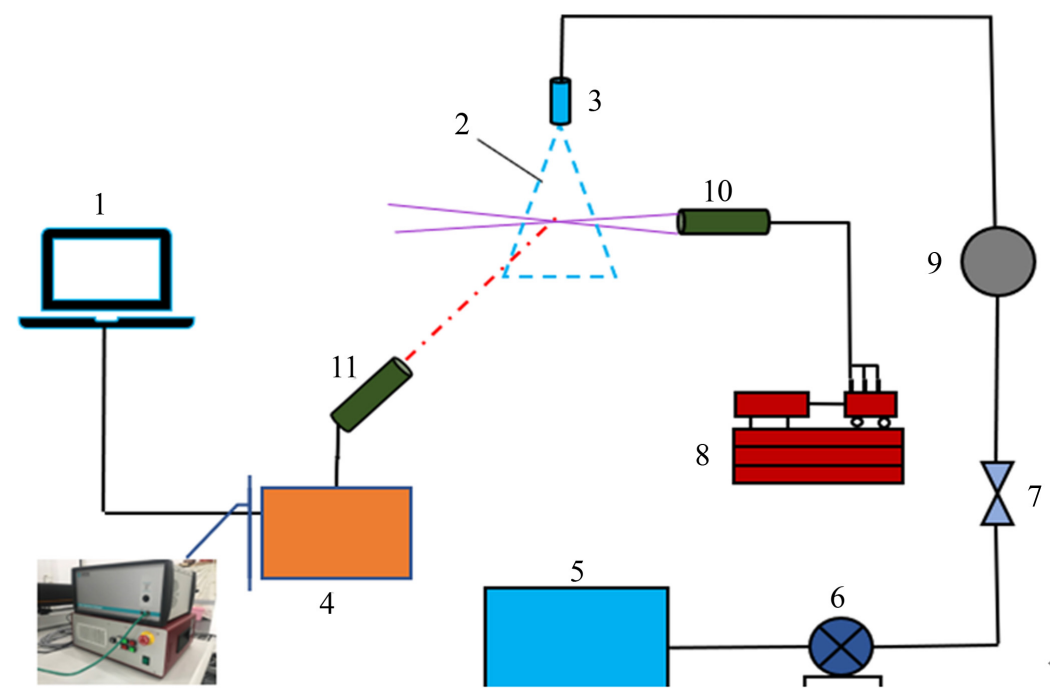

Figure 2. Spraying test platform (1. PC; 2. Spray area; 3. Nozzle; 4. PDA processor; 5. Water tank; 6. Water pump; 7. Water valve; 8. Spectrometer; 9. Flow meter; 10. Transmitting probe; 11 . Receiving probe).

Given a certain pressure, the nozzle atomises and produces a testing atomisation region. Two beams of different lights were produced by the optical splitter of particle dynamic analysis and intersected at the testing region through the transmitting probe laser beam. The receiving probe received data and transmitted to the PDA processer. Lastly, the droplet parameters of the nozzle were gained via PC processing.

\section{Definition of Droplet Parameters}

Here, the following three index parameters of droplets were measured and analysed:

$D_{10}$ : Arithmetic mean diameter refers to the ratio between the sum of diameters of sampling droplet groups and the number of droplet groups:

$$
D_{10}=\frac{1}{N} \sum_{i=1}^{N_{i}} n_{i} D_{i}
$$

$D_{30}$ : Volume mean diameter refers to the diameter corresponding to the mean volume of sampling droplet groups:

$$
D_{30}=\left[\frac{1}{N} \sum_{i=1}^{N_{i}} n_{i} D_{i}^{3}\right]^{1 / 3}
$$

$D_{32}$ : Sauter mean diameter refers to the weighted average of droplet size on the surface area:

$$
D_{32}=\frac{\sum_{i=1}^{N_{i}} n_{i} D_{i}^{3}}{\sum_{i=1}^{N_{i}} D_{i}^{2}}
$$

In the above description of droplet parameters, $D_{i}$ is the diameter of size level $i, N_{i}$ is the number of chosen size levels, $n_{i}$ is the number of droplets in each size 
level, and $N$ is the total number of droplets.

\section{Experiments}

Generally, there is a strong negative correlation between the viscosity of liquid and temperature. Here, the viscosity of spraying solution was tested under the ambient temperature of $25^{\circ} \mathrm{C} \pm 0.5^{\circ} \mathrm{C}$.

\subsection{Viscosity Range Test of Four Pesticides for Phylloxera Control}

To reflect the effects of viscosity of pesticide on droplet parameters of the nozzle, four common pesticides used in citrus control were prepared according to the mixing ratio in the instructions. During the experiment, viscosities were measured with a viscosity meter every 2 min. One viscosity value was read and the mean of three reading data was chosen as the final viscosity. Results are shown in Table 1. Acetamiprid had the minimum viscosity $(1.25 \mathrm{cp})$ among the four pesticides, whereas pyridaben showed the maximum viscosity $(1.80 \mathrm{cp})$.

\subsection{Preparation of Glycerinum Solutions with Different Viscosities}

Because glycerinum and water can mix at any proportion and the viscosity of pure glycerinum is relatively high, four glycerinum solutions with different mass fractions were prepared by mixing glycerinum and water. The results are shown in Table 2. The viscosity of the solution increased as the mass fraction of glycerinum increased. Therefore, the viscosity range covered the viscosities of the common pesticides.

Table 1. Viscosity of four common pesticides.

\begin{tabular}{cccccc}
\hline $\begin{array}{c}\text { Type of } \\
\text { pesticides }\end{array}$ & Mixing ratio & $\begin{array}{c}\text { Viscosity test } \\
\text { I/cp }\end{array}$ & $\begin{array}{c}\text { Viscosity test } \\
\text { II/cp }\end{array}$ & $\begin{array}{c}\text { Viscosity test } \\
\text { III/cp }\end{array}$ & $\begin{array}{c}\text { Mean } \\
\text { viscosity/cp }\end{array}$ \\
\hline Spirodiclofen & $1: 4000$ & 1.69 & 1.61 & 1.62 & 1.64 \\
Pyridaben & $1: 2200$ & 1.81 & 1.80 & 1.80 & 1.80 \\
Acetamiprid & $1: 25,000$ & 1.26 & 1.24 & 1.24 & 1.25 \\
Imidacloprid & $1: 3400$ & 1.49 & 1.50 & 1.51 & 1.50 \\
\hline
\end{tabular}

Table 2. Solution viscosity under different mass fractions of glycerinum.

\begin{tabular}{cccccc}
\hline No. & $\begin{array}{c}\text { Glycerinum } \\
\text { mass fraction/\% }\end{array}$ & $\begin{array}{c}\text { Viscosity test } \\
\text { I/cp }\end{array}$ & $\begin{array}{c}\text { Viscosity test } \\
\text { II/cp }\end{array}$ & $\begin{array}{c}\text { Viscosity test } \\
\text { III/cp }\end{array}$ & $\begin{array}{c}\text { Average } \\
\text { viscosity/cp }\end{array}$ \\
\hline 1 & $0.00 \%$ & 1.10 & 1.11 & 1.11 & 1.10 \\
2 & $12.5 \%$ & 1.29 & 1.31 & 1.30 & 1.30 \\
3 & $22.5 \%$ & 1.62 & 1.63 & 1.63 & 2.19 \\
5 & $32.5 \%$ & 2.18 & 2.2 & 2.19 & 2.99 \\
\hline
\end{tabular}




\subsection{Setting of Sampling Points of Droplet Parameters}

Experiments of the effects of viscosity of the spraying solution on the atomisation performance of the nozzle were divided into tests of axial and radial (given fixed height along the axial direction) droplet parameters of the nozzle under different viscosities of spraying solutions. In atomisation experiments, spraying solutions with different viscosities were prepared by glycerinum, and the nozzle was perpendicular to the ground along the axial direction. The spraying pressure was $0.9 \mathrm{Mpa}$.

The spraying cone angle of the nozzle under a spraying pressure of $1.0 \mathrm{Mpa}$ was measured $44.14^{\circ}$ in early experiments for setting appropriate sampling points in the atomisation region. Hence, the boundary positions of the atomisation region can be determined according to the tangent of the spraying cone angle which is measured in the pre-test, thus enabling the range of the sampling points of droplets to be determined.

When the axial position ( $z$-direction) is fixed, the position of the radial distance ( $x$-direction) can be calculated according to the tangent of the spraying cone angle. However, because of the effect of gravity on the droplets, the actual spraying boundary is smaller than the theoretically calculated boundary. Appropriate sampling points in the atomisation region are determined according to pre-experimental results.

Droplet sampling points along the axial direction were determined as follows. Axial droplet parameters were measured from $z=0 \mathrm{~cm}$ of the atomisation region every $2 \mathrm{~cm}$ by using a PDA to reveal the effects of viscosity on the axial droplet size of the nozzle. The results are shown in Figure 3.

Droplet sampling points along the radial direction were set as follows: radial droplet sizes corresponding to the position where $z=30 \mathrm{~cm}$ and $z=40 \mathrm{~cm}$ were selected. The points were chosen $-8 \mathrm{~cm}-8 \mathrm{~cm}$ at $z=30 \mathrm{~cm}$ and $-10 \mathrm{~cm}-10 \mathrm{~cm}$ at $z=40 \mathrm{~cm}$. Interval of radial ( $x$-direction) sampling points was set at $1 \mathrm{~cm}$ and the droplet parameters on each sampling point were measured by PDA (Figure 4).

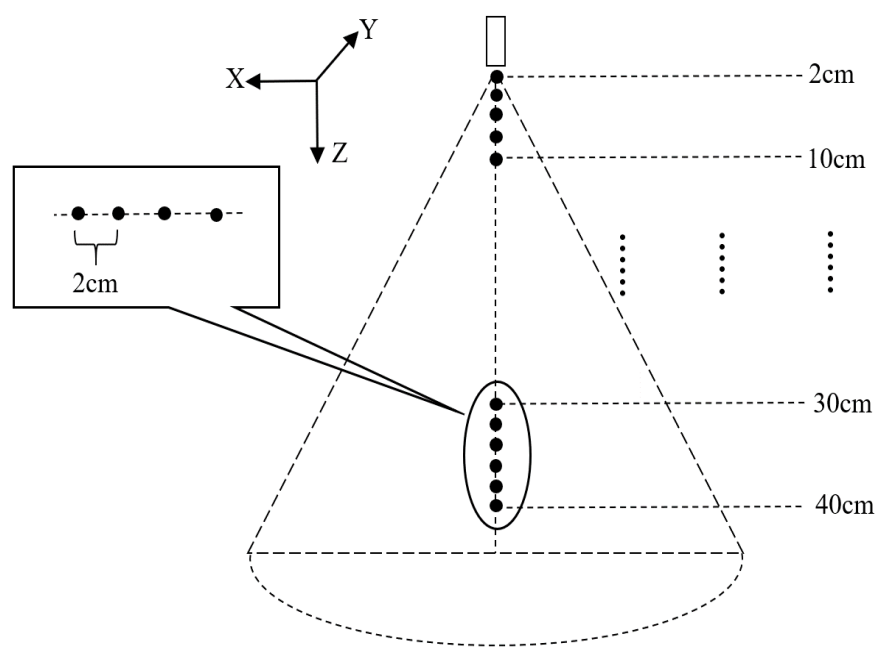

Figure 3. Sampling point along the axial direction. 


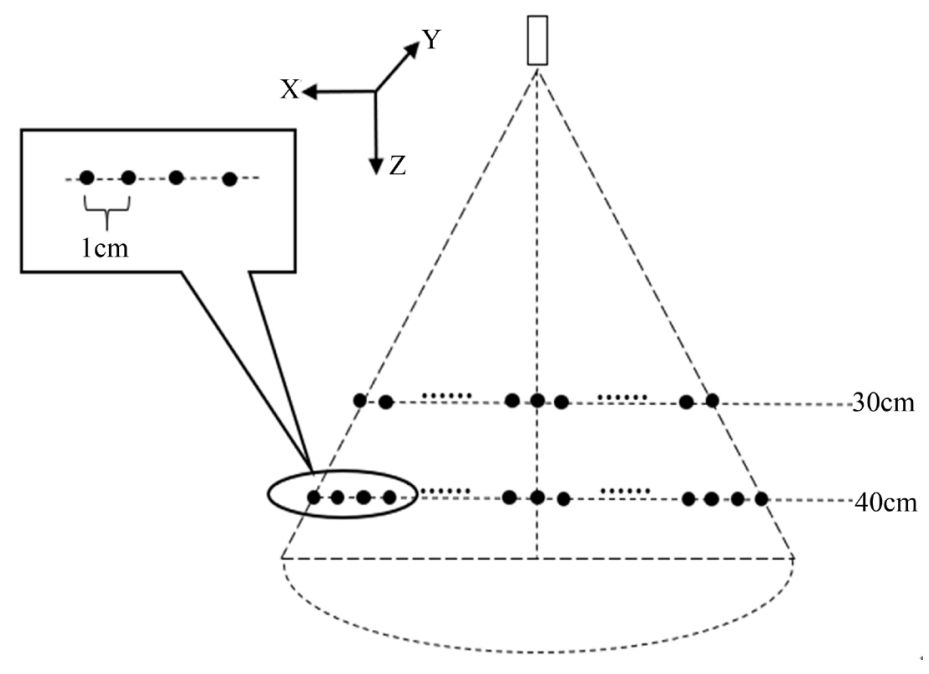

Figure 4. Sampling points along the radial direction.

According to previous studies, many factors can influence the uniformity of spraying fogs. An ideal spraying height is related to the working pressure of the nozzle and the fog distribution characteristics of the nozzle. The environmental wind force is smaller than 3 levels, and the spraying height is adjustable within $35 \mathrm{~cm}-80 \mathrm{~cm}$ [29]. Hence, the sampling range of droplets was chosen within 40 $\mathrm{cm}$ of the spraying height.

\subsection{Spraying Test and Droplet Parameter Test}

Spraying test and droplet parameter test are introduced as follows:

1) Open water valve of PDA and start the laser and preheat it for $15 \mathrm{~min} .2$ ) The laser power is increased to $0.330 \mathrm{~W}$ after stabilising the laser to achieve moderate appropriateness of six beams of lights (e.g. blue, green and purple lights). 3) The maximum sampling time and maximum number of samples are set as $10 \mathrm{~s}$ and 10,000, respectively (sampling stops when sampling time reaches $10 \mathrm{~s}$ or the number of droplet samples exceeds 10,000 ) by the BSA software. 4) Spraying solution with certain viscosity is prepared, and the water pump is initiated until the pipeline flow becomes stable. 5) Sampling range and step length are set to generate the measuring meshing region. Subsequently, measurement begins, and the test interface of BSA software is shown in Figure 5. 6) The spraying solutions of different viscosities are prepared, and the parameters are reset. Repeat Steps 1 - 5. The test field is shown in Figure 6.

\section{Results and Analysis}

\subsection{Axial Distribution Characteristics of Droplet Size}

Axial droplet distribution of nozzle is measured every $2 \mathrm{~cm}$ from the nozzle (Table 3).

The variation curve of droplet parameters with viscosity along the axial direction of the nozzle was drawn according to test data to intuitively understand the 


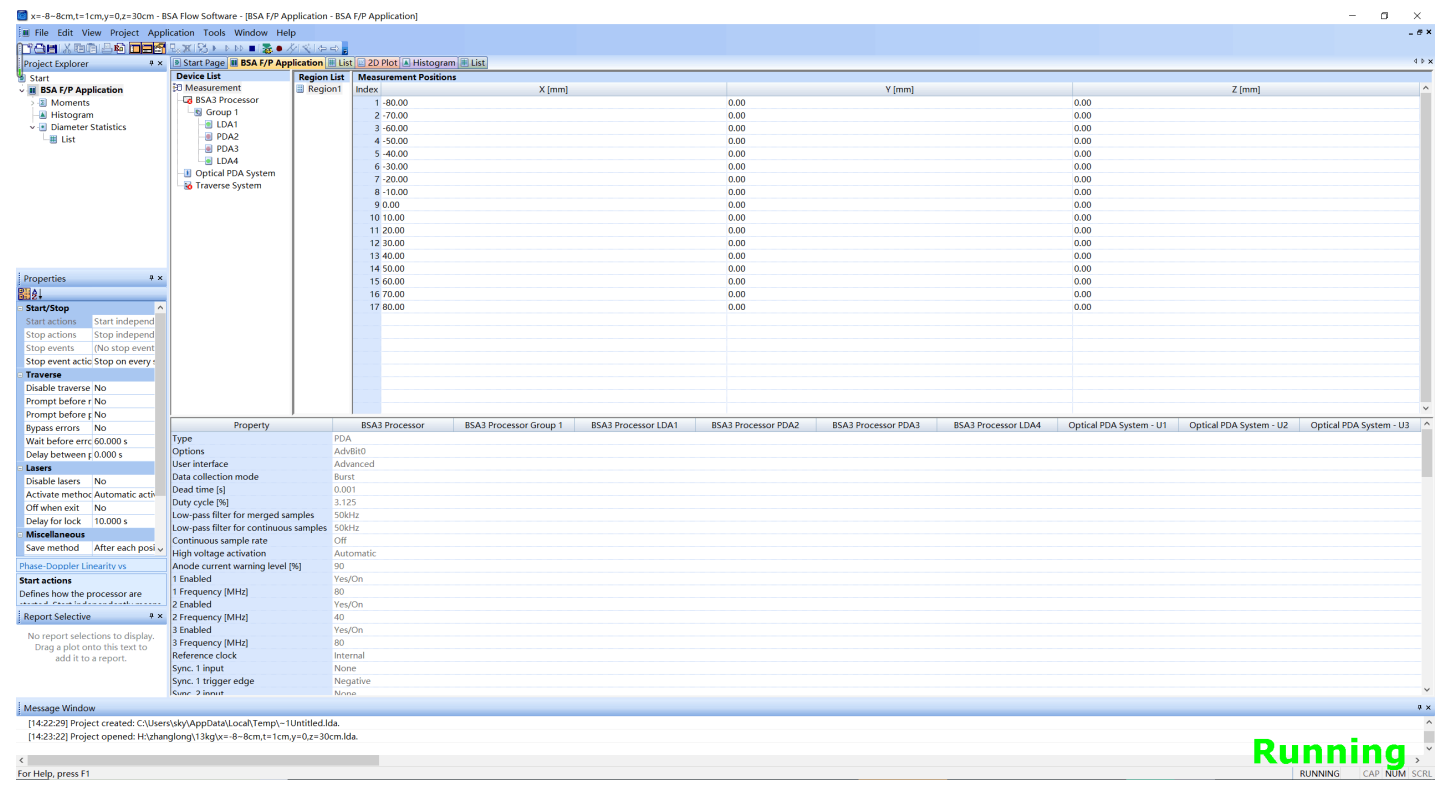

Figure 5. Test interface of BSA software.

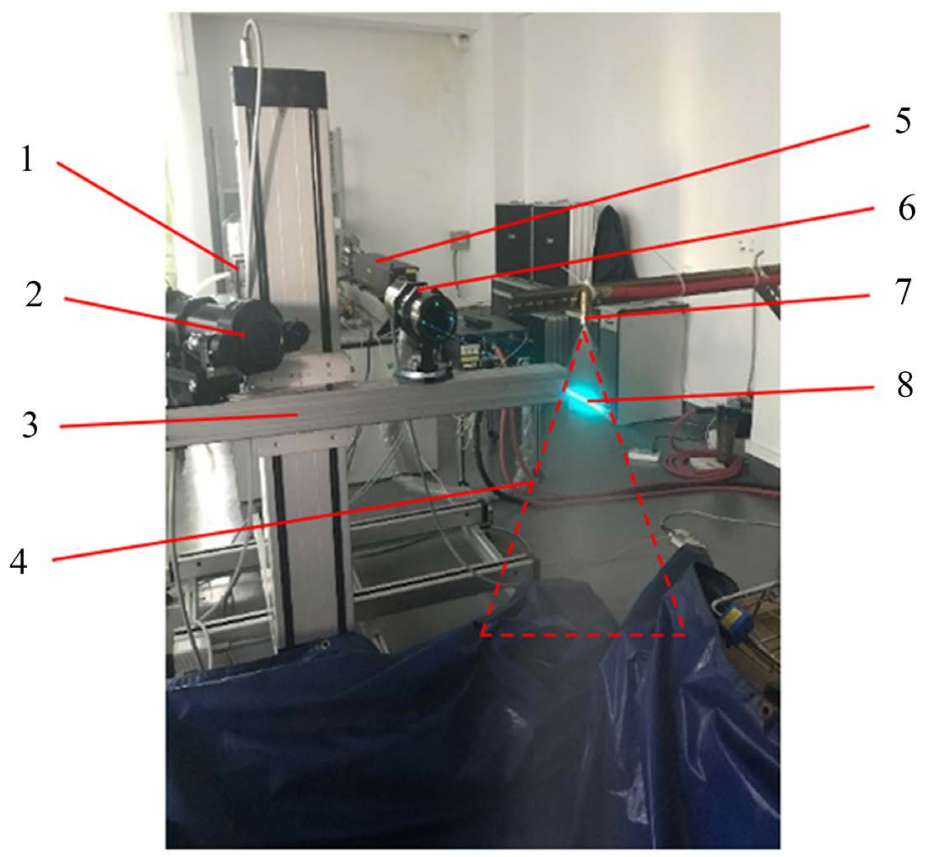

Figure 6. Test field (1. PDA processor; 2. Receiving probe; 3. 3D Mobile Frame; 4. Spray area; 5. Spectrometer; 6. Transmitting probe; 7. Nozzle; 8 . Intersection point of laser beam).

effect of viscosity on droplet parameters along the axial direction of the nozzle. Results are shown in Figures 7-9.

Figures 7-9 show that the droplet size decreased gradually in the $1 \mathrm{~cm}-6 \mathrm{~cm}$ interval. This decrease might be because the efflux flowed out from the nozzle at a high speed in continuum when under pressure. Because of the disturbance of external gas, the liquid surface may produce unstable fluctuations and the wave 
Table 3. Axial droplet parameters under different viscosities (unit: $\mu \mathrm{m}$ ).

\begin{tabular}{|c|c|c|c|c|c|c|c|c|c|c|c|c|c|c|c|}
\hline \multirow{2}{*}{$\begin{array}{c}\text { Axial } \\
\text { distance/cm }\end{array}$} & \multicolumn{3}{|c|}{$1.10 \mathrm{cp}$} & \multicolumn{3}{|c|}{$1.30 \mathrm{cp}$} & \multicolumn{3}{|c|}{$1.63 \mathrm{cp}$} & \multicolumn{3}{|c|}{$2.19 \mathrm{cp}$} & \multicolumn{3}{|c|}{$2.99 \mathrm{cp}$} \\
\hline & $D_{10}$ & $D_{30}$ & $D_{32}$ & $D_{10}$ & $D_{30}$ & $D_{10}$ & $D_{30}$ & $D_{32}$ & $D_{10}$ & $D_{30}$ & $D_{10}$ & $D_{30}$ & $D_{32}$ & $D_{10}$ & $D_{30}$ \\
\hline 0 & $\# \mathrm{~N} / \mathrm{A}$ & $\# \mathrm{~N} / \mathrm{A}$ & $\# \mathrm{~N} / \mathrm{A}$ & $\# \mathrm{~N} / \mathrm{A}$ & $\# \mathrm{~N} / \mathrm{A}$ & $\# \mathrm{~N} / \mathrm{A}$ & $\# \mathrm{~N} / \mathrm{A}$ & $\# \mathrm{~N} / \mathrm{A}$ & $\# \mathrm{~N} / \mathrm{A}$ & $\# \mathrm{~N} / \mathrm{A}$ & \#N/A & $\# \mathrm{~N} / \mathrm{A}$ & $\# \mathrm{~N} / \mathrm{A}$ & $\# \mathrm{~N} / \mathrm{A}$ & \#N/A \\
\hline 2 & 146.7 & 172.4 & 193.8 & 90.4 & 117.2 & 141.5 & 96.0 & 123.2 & 151.2 & 40.8 & 68.3 & 42.7 & 53.7 & 88.1 & 142.9 \\
\hline 4 & 33.9 & 71.3 & 140.1 & 29.9 & 45.4 & 73.4 & 36.1 & 67.4 & 120.2 & 38.9 & 40.8 & 47.1 & 45.2 & 49.1 & 52.8 \\
\hline 6 & 26.9 & 28.3 & 29.7 & 29.7 & 36.2 & 46.9 & 30.1 & 47.2 & 79.1 & 43.3 & 45.2 & 51.5 & 52.3 & 57.6 & 63.0 \\
\hline 8 & 31.1 & 33.2 & 35.2 & 32.5 & 35.1 & 37.8 & 30.2 & 34.6 & 39.0 & 47.8 & 49.6 & 53.4 & 54.8 & 60.8 & 67.0 \\
\hline 10 & 33.0 & 35.4 & 37.7 & 34.3 & 37.2 & 40.2 & 35.2 & 38.1 & 43.0 & 49.4 & 51.3 & 58.9 & 61.6 & 68.1 & 74.8 \\
\hline 12 & 33.9 & 37.1 & 40.6 & 36.1 & 39.8 & 43.6 & 36.9 & 40.3 & 45.7 & 53.3 & 56.0 & 61.7 & 65.1 & 72.3 & 79.7 \\
\hline 14 & 35.1 & 38.4 & 41.8 & 37.2 & 41.5 & 46.2 & 37.9 & 40.7 & 46.4 & 55.2 & 58.3 & 65.9 & 68.0 & 75.0 & 82.0 \\
\hline 16 & 36.1 & 39.9 & 43.9 & 38.5 & 43.2 & 48.2 & 39.8 & 43.4 & 50.3 & 58.7 & 62.2 & 70.3 & 69.7 & 76.8 & 84.1 \\
\hline 18 & 37.4 & 41.7 & 46.2 & 39.8 & 44.9 & 50.3 & 40.4 & 45.3 & 52.6 & 61.2 & 65.5 & 75.5 & 73.3 & 82.0 & 91.2 \\
\hline 20 & 38.3 & 43.1 & 48.2 & 41.0 & 46.6 & 52.8 & 41.5 & 47.9 & 55.5 & 64.3 & 69.6 & 80.5 & 74.2 & 82.1 & 90.1 \\
\hline 22 & 39.6 & 45.1 & 51.1 & 42.6 & 48.7 & 55.5 & 43.3 & 50.9 & 59.9 & 66.5 & 73.1 & 80.7 & 79.1 & 87.7 & 96.9 \\
\hline 24 & 40.0 & 45.8 & 52.3 & 43.7 & 50.8 & 58.8 & 44.7 & 51.3 & 60.5 & 66.1 & 72.9 & 88.1 & 80.6 & 89.4 & 98.5 \\
\hline 26 & 41.1 & 47.4 & 54.5 & 45.3 & 53.0 & 61.8 & 46.6 & 54.4 & 65.1 & 70.8 & 78.9 & 101.7 & 84.2 & 94.3 & 105.1 \\
\hline 28 & 42.0 & 49.0 & 56.9 & 46.7 & 54.9 & 64.4 & 47.5 & 56.2 & 68.0 & 78.5 & 89.4 & 98.6 & 85.8 & 96.0 & 106.9 \\
\hline 30 & 43.1 & 51.2 & 60.8 & 47.3 & 55.8 & 65.4 & 47.6 & 59.3 & 72.2 & 74.5 & 85.6 & 100.2 & 86.5 & 98.7 & 112.3 \\
\hline 32 & 44.0 & 52.1 & 61.4 & 48.4 & 57.6 & 68.2 & 49.6 & 61.8 & 75.4 & 75.6 & 87.0 & 112.4 & 82.3 & 97.3 & 114.0 \\
\hline 34 & 44.5 & 53.0 & 62.8 & 49.8 & 59.7 & 71.3 & 50.5 & 63.8 & 78.8 & 82.1 & 96.1 & 112.4 & 87.0 & 100.2 & 114.9 \\
\hline 36 & 45.6 & 54.8 & 65.5 & 51.4 & 62.2 & 75.0 & 52.1 & 66.4 & 82.6 & 75.9 & 88.2 & 102.8 & 90.0 & 104.2 & 120.0 \\
\hline 38 & 47.1 & 57.2 & 69.2 & 53.0 & 64.9 & 79.2 & 53.8 & 68.8 & 86.0 & 79.6 & 93.8 & 110.5 & 91.3 & 106.1 & 122.8 \\
\hline 40 & 49.1 & 60.6 & 74.4 & 54.0 & 66.4 & 81.2 & 54.7 & 70.0 & 87.7 & 83.9 & 97.7 & 113.5 & 88.6 & 102.6 & 118.2 \\
\hline
\end{tabular}

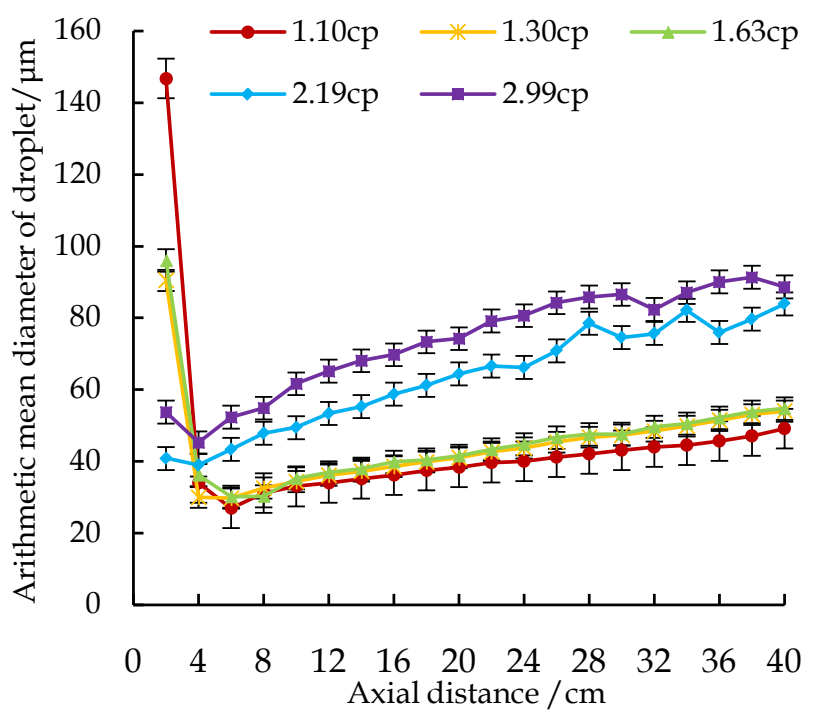

Figure 7. Arithmetic mean diameter along the axial direction. 


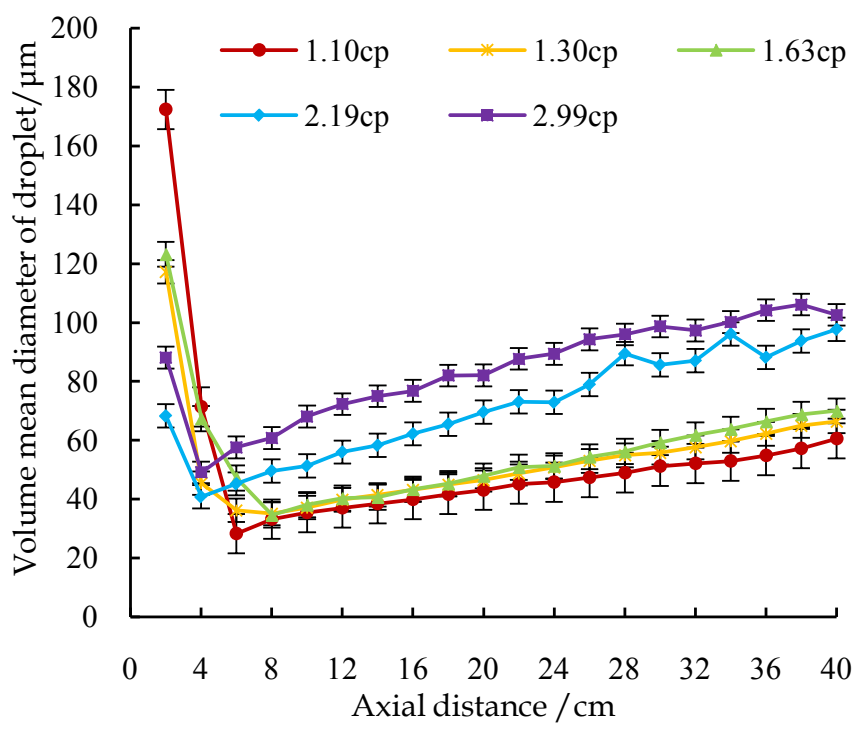

Figure 8. Volume mean diameter of droplets along the axial direction.

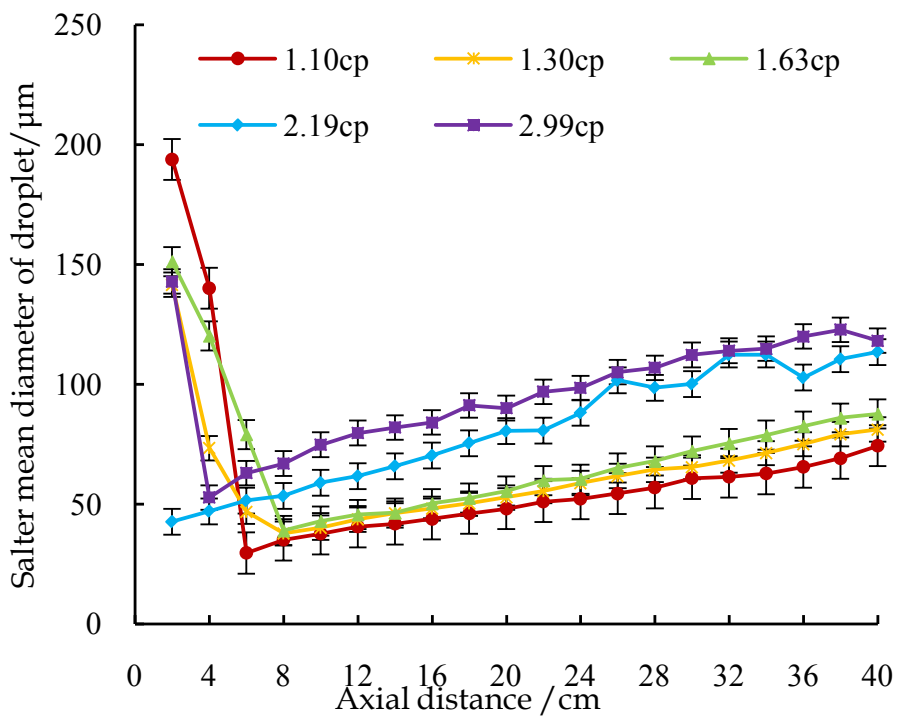

Figure 9. Sauter mean diameter along the axial direction.

amplitude of the liquid surface may rapidly increase when the liquid has a high flow rate. Lastly, the wave crest was removed and large droplets were formed.

As the jetting distance increased, the wave amplitude of such surface wave gradually increased to split the liquid into large droplets. When the droplet diameter exceeded a certain threshold, the droplets were further broken into smaller liquid droplets under surrounding air shearing stress. Hence, the wave amplitude declined gradually in the $1 \mathrm{~cm}-6 \mathrm{~cm}$ range.

Rayleigh theory outputs the maximum instability ratio of the viscous jet. In other words, there is a minimum disturbance wavelength $\lambda_{\min }$, and the jet might be separated into the disturbance wavelength of liquid drops $\left(\lambda_{\mathrm{opt}}\right)$. When the initial disturbance close to the nozzle outlet is smaller than $\lambda_{\min }$, the jet disturbance 
decreases because of surface tension. When the initial disturbance wavelength is higher than $\lambda_{\min }$, the disturbance wave amplitude increases and the jet is broken. For non-viscous fluid [30],

$$
\begin{gathered}
\lambda_{\text {min }}=\pi d \\
\lambda_{\text {opt }}=\sqrt{2} \pi d
\end{gathered}
$$

For viscous fluid,

$$
\begin{gathered}
\lambda_{\min }=\pi d \\
\lambda_{\mathrm{opt}}=\sqrt{2} \pi d\left[1+\frac{3 u_{l}}{\sqrt{\rho_{l} \sigma_{l} d}}\right]^{1 / 2}
\end{gathered}
$$

where, $u_{l}$ is the liquid viscosity, $\rho_{l}$ is the liquid density, $\sigma_{l}$ is the liquid surface tension, and $d$ is the jet diameter. Hence, the $\lambda_{\min }$ of the viscous fluid is the same as that of non-viscous fluid, but the $\lambda_{\text {opt }}$ of viscous fluid is significantly higher than that of non-viscous fluid.

Experiments showed that given the same atomisation conditions, the density $\left(\rho_{I}\right)$, surface tension $\left(\sigma_{I}\right)$ and jet diameter $(d)$ of the spraying solution with different viscosities were similar. The viscosity of the spraying solution was the main influencing factor of the disturbance wavelength $\left(\lambda_{\text {opt }}\right)$. Thus, as the viscosity of the spraying solution increased, the higher might separate the jetting flow into droplets and more energy was needed. In Figures 7-9, the droplet size was positively related to the viscosity of the spraying solution at the same position. This relationship was mainly because it is more difficult to atomise a spraying solution with a higher viscosity and because the atomisation needs more atomising energy under the same jet pressure. Hence, a spraying solution with high viscosity forms large droplets rather than small droplets.

In the $8 \mathrm{~cm}-40 \mathrm{~cm}$ interval, droplet size under differential axial distances increased gradually from the near position to the far position. Because of the dominant controlling of droplets by gravity and air resistance along the axial direction of the nozzle, droplets may drop at an accelerating speed, during which droplets agglomerate and collide to increase droplet size gradually and form big droplets.

\subsection{Distribution of Axial Droplet Speed}

The droplet speed is one of the barriers against effective utilisation. Droplets may collide at the target and then splash if the droplet speed is too high, thus resulting in pesticide waste. In contrast, droplets cannot effectively arrive at the target if the droplet speed is too low. To further analyse the moving laws of droplets under different viscosities, the axial droplet speed under different viscosities was tested (Table 4).

Variation curves of droplet speed with axial distance under different viscosities were drawn for an intuitive understanding of the relationship between droplet speed from an agricultural nozzle and viscosity of droplets (Figure 10). 
Table 4. Droplet speed under different viscosities (Units: $\mathrm{m} / \mathrm{s}$ ).

\begin{tabular}{|c|c|c|c|c|c|}
\hline Axial distance/cm & $1.10 \mathrm{cp}$ & $1.30 \mathrm{cp}$ & $1.63 \mathrm{cp}$ & $2.19 \mathrm{cp}$ & $2.99 \mathrm{cp}$ \\
\hline 0 & $\# \mathrm{~N} / \mathrm{A}$ & $\# \mathrm{~N} / \mathrm{A}$ & $\# \mathrm{~N} / \mathrm{A}$ & $\# \mathrm{~N} / \mathrm{A}$ & \#N/A \\
\hline 2 & 9.56 & 10.47 & 10.02 & 9.64 & 7.99 \\
\hline 4 & 13.09 & 12.80 & 12.35 & 12.00 & 11.42 \\
\hline 6 & 13.36 & 13.06 & 12.77 & 11.47 & 11.64 \\
\hline 8 & 13.23 & 12.90 & 12.93 & 11.24 & 11.19 \\
\hline 10 & 13.05 & 12.82 & 12.80 & 11.07 & 10.88 \\
\hline 12 & 13.05 & 12.76 & 12.80 & 10.25 & 10.09 \\
\hline 14 & 13.04 & 12.67 & 12.76 & 10.16 & 10.04 \\
\hline 16 & 13.00 & 12.62 & 12.63 & 9.64 & 9.01 \\
\hline 18 & 12.90 & 12.50 & 12.60 & 9.47 & 8.68 \\
\hline 20 & 12.73 & 12.39 & 12.43 & 8.85 & 8.44 \\
\hline 22 & 12.65 & 12.27 & 12.20 & 9.02 & 7.74 \\
\hline 24 & 12.70 & 12.03 & 12.16 & 8.61 & 7.67 \\
\hline 26 & 12.59 & 11.85 & 11.88 & 8.23 & 7.23 \\
\hline 28 & 12.34 & 11.67 & 11.78 & 6.86 & 6.77 \\
\hline 30 & 12.12 & 11.63 & 11.33 & 8.00 & 6.46 \\
\hline 32 & 12.09 & 11.39 & 11.09 & 7.89 & 6.44 \\
\hline 34 & 12.02 & 11.25 & 10.92 & 6.67 & 6.12 \\
\hline 36 & 11.82 & 10.89 & 10.64 & 7.44 & 5.84 \\
\hline 38 & 11.53 & 10.52 & 10.34 & 7.11 & 5.66 \\
\hline 40 & 11.50 & 10.51 & 10.30 & 6.12 & 5.34 \\
\hline
\end{tabular}

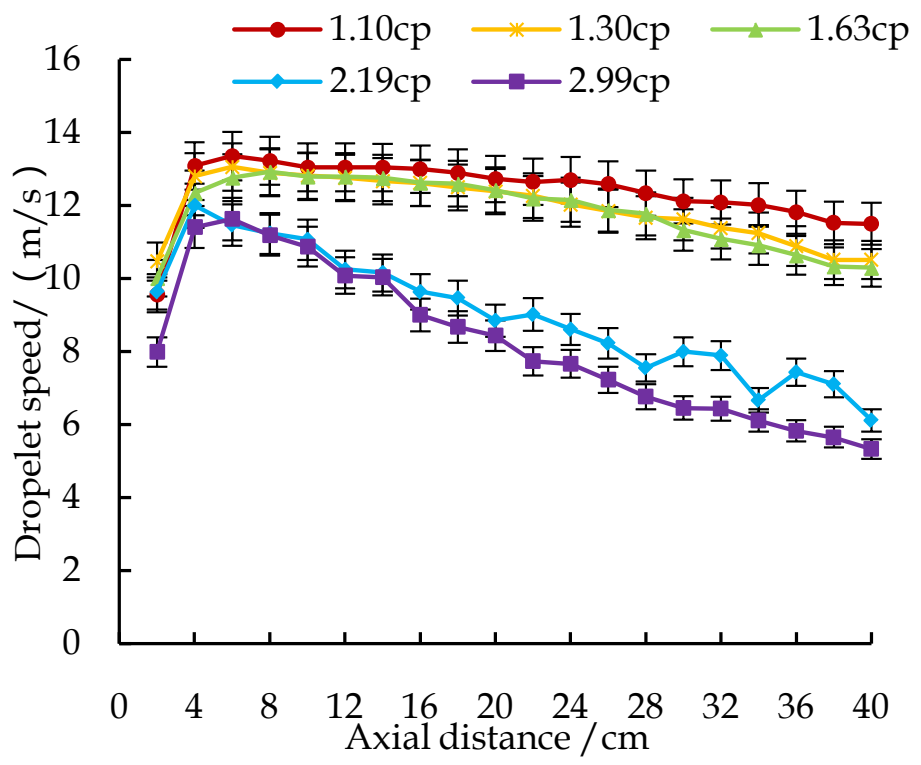

Figure 10. Variation curves of axial droplet speed. 
The variation trend of the droplet speed is shown in Figure 10:

1) The variation law of the droplet speed was independent of the viscosity of the spraying solution. According to the axial distance, changes of droplet speed could be divided into two intervals, and the droplet speed changed differently in the different regions, as follows: a) droplet speed increased gradually in the $0 \mathrm{~cm}$ - $6 \mathrm{~cm}$ interval. A liquid film was formed after the spraying solution was ejected rotationally from the nozzle, producing shear stress because of the speed difference in air. Therefore, the liquid surface developed deformations. Under this circumstance, the external force was higher than the internal force of the liquid (viscous force) to break the liquid film into large droplets. During this process, the droplet speed decreased at an accelerated rate because of an inertia force until no more droplets broke when the shear stress was equal to the internal force of the liquid. At that moment, the acceleration speed of the droplet was 0 and the droplet had balanced stresses. b) The atomised droplet particles in the $6 \mathrm{~cm}$ $40 \mathrm{~cm}$ interval formed large droplets again through mutual collision. Accordingly, droplet speed decreased the air resistance and was stronger than the gravitational force.

2) At the same position ( $z=30 \mathrm{~cm}$ in Figure 10), the droplet speed was negatively correlated with the viscosity of the spraying solution. Table 3 shows that the droplet size was larger when the viscosity of the spraying solution was high and when atomising it was more difficult. Because of the same injection pressure, liquid with a high viscosity consumed more energy.

To further understand the relationship between the droplet speed and size, the droplet speed vector map (for the convenient analysis, data when viscosity is $1.63 \mathrm{cp}$ are exhibited) along the axial direction ( $z$-direction) was drawn with BSA (Figure 11). The arrow direction represents the moving direction of the droplets. The arrow length on dots reflects the droplet size, and the size of dots reflects the volume mean diameter of the droplets.

\subsection{Droplet Spectral Analysis}

To further analyse the distribution of droplet size in droplet groups under different viscosities, the droplet spectrum at $z=20 \mathrm{~cm}$ was analysed (Figure 12). In Figures 12(a)-(e), the peak of the droplet spectrum gradually moves toward the right, indicating that the proportion of big droplets is positively related to the viscosity of the spraying solution.

\subsection{Radial Droplet Size Distribution}

The droplet sizes along the radial direction (y-direction) under different viscosities

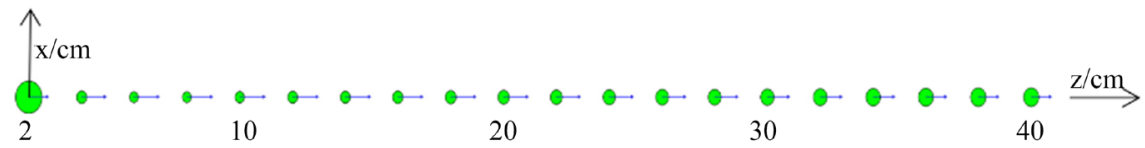

Figure 11. Droplet speed vector map along the axial direction. 


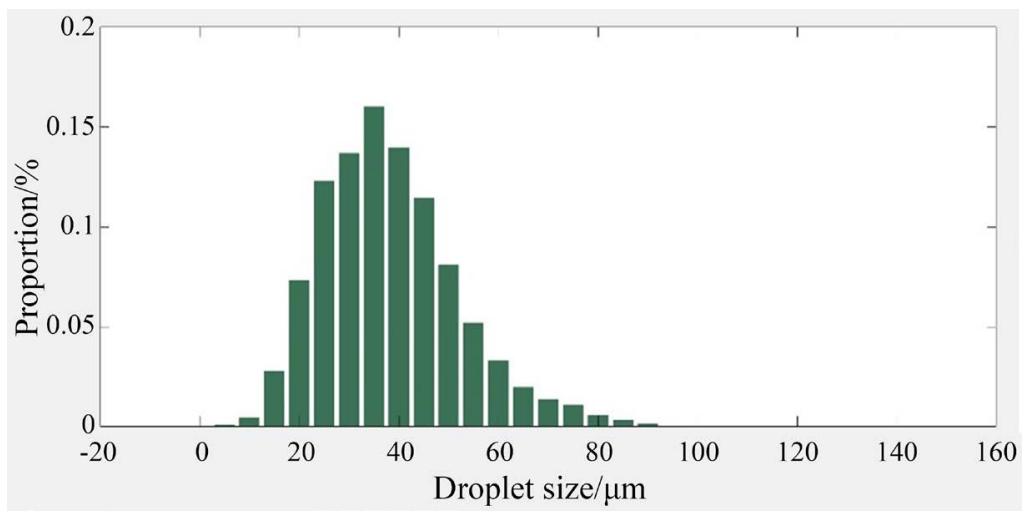

(a)

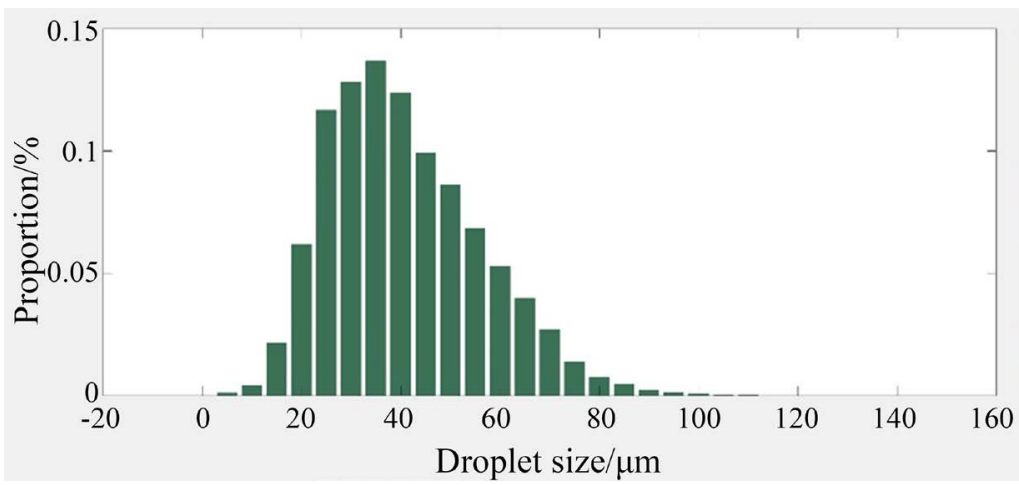

(b)

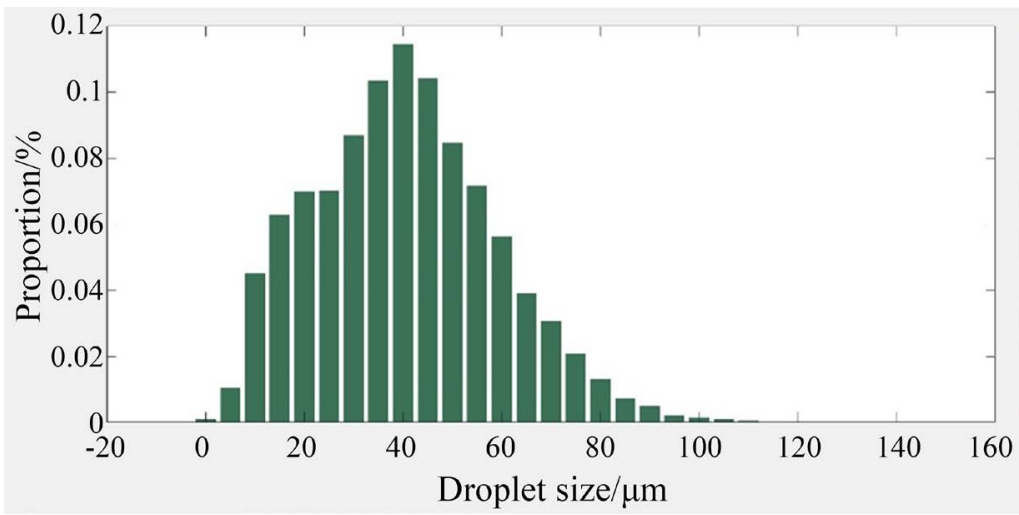

(c)

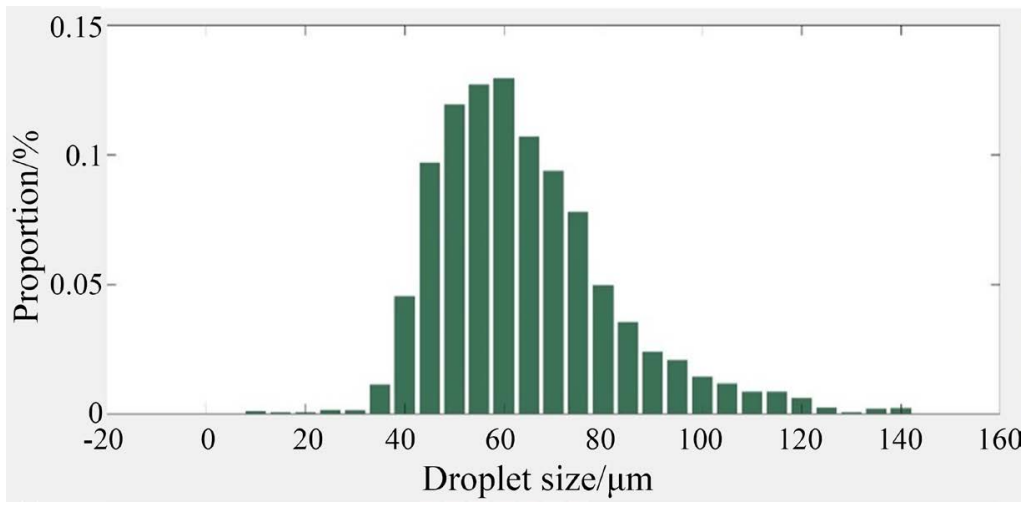

(d) 


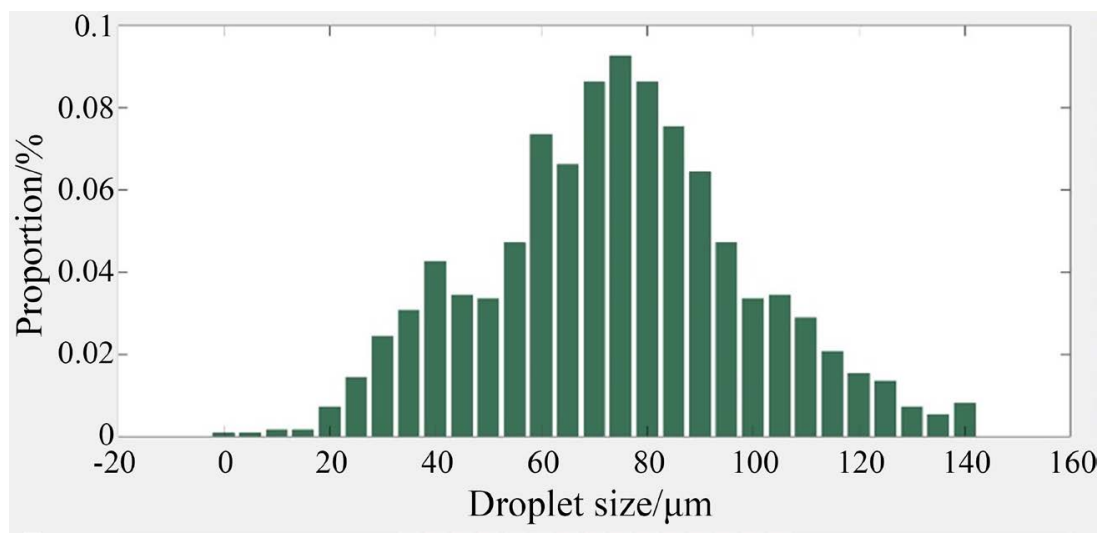

(e)

Figure 12. Droplet spectrum at $z=20 \mathrm{~cm}$ under different viscosities. (a) $1.10 \mathrm{cp}$; (b) 1.30 cp; (c) $1.63 \mathrm{cp}$; (d) $2.19 \mathrm{cp}$; (e) $2.99 \mathrm{cp}$.

at $z=30 \mathrm{~cm}$ and $z=40 \mathrm{~cm}$ are shown in Table 5 and Table 6, respectively. The variation law of droplet size with radial distance at the same axis position is discussed based on the results in Table 5 and Table 6.

The variation curves of the volume mean diameter of the droplets $\left(D_{30}\right)$ with radial distance were drawn (Figure 13 and Figure 14) to understand the viscosity effects of the spraying solution on the radial droplet size (for convenient analysis, $z=30 \mathrm{~cm}$ ). In Figure 13, radial droplet size changed with distance. In addition, the variation curve of $D_{30}$ with viscosity at $z=30 \mathrm{~cm}$ was drawn (Figure 14).

Figure 13 shows that that under the same viscosity of spraying solution, droplet size was positively related to radial distance and the minimum droplet size was always at the axis. Droplet sizes at two radial sizes were approximately symmetric. The volume mean diameter of the droplet at the same position was positively related to the spraying solution viscosity.

Ohnesorg indicated that droplet size after jet breaking was mainly determined by the nozzle diameter and density, viscous force and surface tension of the liquid. Such relations were described by a dimensionless number $Z$ [30]. $Z$ is related to density, viscosity force and surface tension of the liquid to some extent:

$$
Z=\frac{u_{l}}{\sqrt{\rho_{l} \sigma_{l} d_{0}}}
$$

where, $u_{l}$ is the liquid viscosity, $\rho_{l}$ is the liquid density, $\sigma_{l}$ is the surface tension, and $d_{0}$ is the initial diameter of the jet.

Under the same experimental conditions, the density, surface tension and jet flow diameter of the spraying solution with different viscosities changed slightly. Hence, the liquid viscosity was the main cause of the liquid breaking in atomisation. Viscosity served as damp during the increase of disturbance wave of the jet surface. Figure 14 shows that $Z$ declined as the viscosity decreased indirectly through the reduction of resistance. Consequently, the droplet size was smaller. 
Table 5. Distribution of radial droplet size at $z=30 \mathrm{~cm}$ under different viscosities (unit: $\mu \mathrm{m}$ ).

\begin{tabular}{|c|c|c|c|c|c|c|c|c|c|c|c|c|c|c|c|}
\hline \multirow{2}{*}{$\begin{array}{c}\text { Radial } \\
\text { distance/cm }\end{array}$} & \multicolumn{3}{|c|}{$1.10 \mathrm{cp}$} & \multicolumn{3}{|c|}{$1.30 \mathrm{cp}$} & \multicolumn{3}{|c|}{$1.63 \mathrm{cp}$} & \multicolumn{3}{|c|}{$2.19 \mathrm{cp}$} & \multicolumn{3}{|c|}{$2.99 \mathrm{cp}$} \\
\hline & $D_{10}$ & $D_{30}$ & $D_{32}$ & $D_{10}$ & $D_{30}$ & $D_{10}$ & $D_{30}$ & $D_{32}$ & $D_{10}$ & $D_{30}$ & $D_{10}$ & $D_{30}$ & $D_{32}$ & $D_{10}$ & $D_{30}$ \\
\hline-8 & 144.5 & 150.6 & 170.2 & 132.0 & 152.5 & 171.8 & 135.2 & 157.5 & 177.8 & 153.1 & 165.7 & 176.9 & 168.5 & 175.0 & 180.2 \\
\hline-7 & 137 & 134.1 & 149.4 & 118.4 & 139.1 & 159 & 121.4 & 143.4 & 164.6 & 143.4 & 158.7 & 173.4 & 153.0 & 166.6 & 173.5 \\
\hline-6 & 119.6 & 117.0 & 143.5 & 99.6 & 121.5 & 144.1 & 100.3 & 121.6 & 143.3 & 121.4 & 127.4 & 153.8 & 136.4 & 150.5 & 158.0 \\
\hline-5 & 102.2 & 103.0 & 125.6 & 85.2 & 105.4 & 127.6 & 95.2 & 114.5 & 134.5 & 111.7 & 123.0 & 144.7 & 126.2 & 129.8 & 149.2 \\
\hline-4 & 85.3 & 88.8 & 118.8 & 82.4 & 101.3 & 122.4 & 79.4 & 98.0 & 118.2 & 99.5 & 109.3 & 126.5 & 123.7 & 126.2 & 129.6 \\
\hline-3 & 72.2 & 73.9 & 105.1 & 71.5 & 88.8 & 108.9 & 71.0 & 88.7 & 108.2 & 88.9 & 103.8 & 119.0 & 118.5 & 111.4 & 114.5 \\
\hline-2 & 61.4 & 65.7 & 89.4 & 59.4 & 73.6 & 90.8 & 64.5 & 80.5 & 98.2 & 74.9 & 91.9 & 105.5 & 102.3 & 95.7 & 105.8 \\
\hline-1 & 51.6 & 57.9 & 73.7 & 51.7 & 61.8 & 73.4 & 58.7 & 72.7 & 88.4 & 59.4 & 84.9 & 97.8 & 92.4 & 86.8 & 104.7 \\
\hline 0 & 48.4 & 51.7 & 66.3 & 48.7 & 57.3 & 67.3 & 53.0 & 63.7 & 75.1 & 57.8 & 73.5 & 83.5 & 76.3 & 82.6 & 92.1 \\
\hline 1 & 51.0 & 56.6 & 70.1 & 50.0 & 60.1 & 71.8 & 54.3 & 66.4 & 79.8 & 69.8 & 74.8 & 85.0 & 86.5 & 84.2 & 107.4 \\
\hline 2 & 63.7 & 63.1 & 86.6 & 57.4 & 72.1 & 89.7 & 62.1 & 78.0 & 96.1 & 85.1 & 82.8 & 102.8 & 99.2 & 96.8 & 128.9 \\
\hline 3 & 78.0 & 75.3 & 94.1 & 62.2 & 79.4 & 100.4 & 70.4 & 88.9 & 109.5 & 87.8 & 94.1 & 119.2 & 106.3 & 100.6 & 133.5 \\
\hline 4 & 88.6 & 89.6 & 113.3 & 72.5 & 92.6 & 115.6 & 81.7 & 103.3 & 126.9 & 102.2 & 111.9 & 135.4 & 113.4 & 117.2 & 143.0 \\
\hline 5 & 97.0 & 111.8 & 136.8 & 93.3 & 115.5 & 139.1 & 99.2 & 122.8 & 147.0 & 114.0 & 127.7 & 157.8 & 127.7 & 135.8 & 161.3 \\
\hline 6 & 107.7 & 129.8 & 151.7 & 110.7 & 133.5 & 156.0 & 116.9 & 139.2 & 160.8 & 128.2 & 149.9 & 161.0 & 139.5 & 153.3 & 171.7 \\
\hline 7 & 120.0 & 142.2 & 163.7 & 127.6 & 150.1 & 171.5 & 133.9 & 156.9 & 178.5 & 137.6 & 166.3 & 184.3 & 146.4 & 171.2 & 188.8 \\
\hline 8 & 142.9 & 156.0 & 181.1 & 135.3 & 160.1 & 182.7 & 147.7 & 170.2 & 190.6 & 154.5 & 176.2 & 195.1 & 155.3 & 181.0 & 205.4 \\
\hline
\end{tabular}

Table 6. Distribution of radial droplet size at $z=40 \mathrm{~cm}$ under different viscosities (unit: $\mu \mathrm{m}$ ).

\begin{tabular}{|c|c|c|c|c|c|c|c|c|c|c|c|c|c|c|c|}
\hline \multirow{2}{*}{$\begin{array}{c}\text { Radial } \\
\text { distance/cm }\end{array}$} & \multicolumn{3}{|c|}{$1.10 \mathrm{cp}$} & \multicolumn{3}{|c|}{$1.30 \mathrm{cp}$} & \multicolumn{3}{|c|}{$1.63 \mathrm{cp}$} & \multicolumn{3}{|c|}{$2.19 \mathrm{cp}$} & \multicolumn{3}{|c|}{$2.99 \mathrm{cp}$} \\
\hline & $D_{10}$ & $D_{30}$ & $D_{32}$ & $D_{10}$ & $D_{30}$ & $D_{10}$ & $D_{30}$ & $D_{32}$ & $D_{10}$ & $D_{30}$ & $D_{10}$ & $D_{30}$ & $D_{32}$ & $D_{10}$ & $D_{30}$ \\
\hline-10 & 155.5 & 169.0 & 181.0 & 148.4 & 169.0 & 187.9 & 158.8 & 178.9 & 196.1 & 172.6 & 182.0 & 201.6 & 193.4 & 203.9 & 233.3 \\
\hline-9 & 145.9 & 161.3 & 175.0 & 140.7 & 160.1 & 177.7 & 144.1 & 165.5 & 185.6 & 164.0 & 178.5 & 182.5 & 171.0 & 194.7 & 206.6 \\
\hline-8 & 139.1 & 155.9 & 171.1 & 126.8 & 147.4 & 167.0 & 122.1 & 146.3 & 169.5 & 151.4 & 167.6 & 171.6 & 159.9 & 164.2 & 177.5 \\
\hline-7 & 112.5 & 132.4 & 151.7 & 123.4 & 144.3 & 164.0 & 115.6 & 137.3 & 158.6 & 141.1 & 156.6 & 160.0 & 149.0 & 162.3 & 175.2 \\
\hline-6 & 105.6 & 124.3 & 142.5 & 104.5 & 126.6 & 149.0 & 101.1 & 123.7 & 146.5 & 128.5 & 144.1 & 156.4 & 140.5 & 154.0 & 167.2 \\
\hline-5 & 106.0 & 125.3 & 130.2 & 91.7 & 112.7 & 134.8 & 90.5 & 112.9 & 136.3 & 129.8 & 143.2 & 146.2 & 132.3 & 137.6 & 153.2 \\
\hline-4 & 83.9 & 104.4 & 106.2 & 68.0 & 86.7 & 108.8 & 80.6 & 102.6 & 126.3 & 116.5 & 131.1 & 134.4 & 112.6 & 134.8 & 136.0 \\
\hline-3 & 62.3 & 79.4 & 99.7 & 63.8 & 81.4 & 102.6 & 69.4 & 90.3 & 114.3 & 83.2 & 117.6 & 115.9 & 100.5 & 124.9 & 134.8 \\
\hline-2 & 58.3 & 73.5 & 91.8 & 57.3 & 72.3 & 90.6 & 65.9 & 86.6 & 110.5 & 77.3 & 98.0 & 111.9 & 90.3 & 119.3 & 121.7 \\
\hline-1 & 51.9 & 64.3 & 79.3 & 53.5 & 66.1 & 81.3 & 57.3 & 74.4 & 94.6 & 64.5 & 86.1 & 98.4 & 84.4 & 108.1 & 105.2 \\
\hline 0 & 51.5 & 63.4 & 72.5 & 51.0 & 61.9 & 74.9 & 53.7 & 67.8 & 82.0 & 64.1 & 71.4 & 88.0 & 82.7 & 93.6 & 104.2 \\
\hline 1 & 52.0 & 64.6 & 72.3 & 50.9 & 62.4 & 76.6 & 53.1 & 66.8 & 84.0 & 73.2 & 84.8 & 84.3 & 85.3 & 105.2 & 107.2 \\
\hline 2 & 60.5 & 77.0 & 86.6 & 55.7 & 71.0 & 89.8 & 57.9 & 75.0 & 94.9 & 77.3 & 86.8 & 99.0 & 86.4 & 116.5 & 111.9 \\
\hline 3 & 66.2 & 83.8 & 94.0 & 61.1 & 77.8 & 98.0 & 66.5 & 86.8 & 110.1 & 84.5 & 92.2 & 111.4 & 98.7 & 123.6 & 127.3 \\
\hline
\end{tabular}




\section{Continued}

\begin{tabular}{llllllllllllllll}
\hline 4 & 78.6 & 97.4 & 107.6 & 73.7 & 93.0 & 114.7 & 84.6 & 106.2 & 129.1 & 104.1 & 119.4 & 131.7 & 114.6 & 139.2 & 135.6 \\
5 & 85.2 & 105.6 & 127.0 & 81.3 & 102.6 & 126.1 & 95.3 & 118.4 & 141.7 & 119.4 & 134.7 & 149.6 & 138.6 & 141.4 & 148.3 \\
6 & 94.3 & 115.4 & 136.6 & 109.1 & 131.4 & 153.3 & 102.2 & 126.3 & 150.7 & 128.1 & 148.1 & 153.8 & 141.5 & 157.8 & 170.0 \\
7 & 108.8 & 131.5 & 153.5 & 117.7 & 142.0 & 165.5 & 125.9 & 149.1 & 170.9 & 144.5 & 156.5 & 181.9 & 153.7 & 166.9 & 184.5 \\
8 & 124.4 & 145.7 & 165.5 & 132.0 & 154.9 & 176.4 & 134.5 & 156.9 & 177.6 & 149.5 & 165.9 & 189.3 & 158.0 & 172.1 & 190.6 \\
9 & 140.7 & 162.5 & 182.0 & 144.9 & 167.3 & 187.4 & 151.3 & 172.6 & 191.6 & 163.1 & 173.1 & 194.5 & 177.3 & 193.1 & 201.9 \\
10 & 149.6 & 172.0 & 192.1 & 151.0 & 173.5 & 193.9 & 149.9 & 176.3 & 199.7 & 167.4 & 176.1 & 213.0 & 180.3 & 205.2 & 223.4 \\
\hline
\end{tabular}

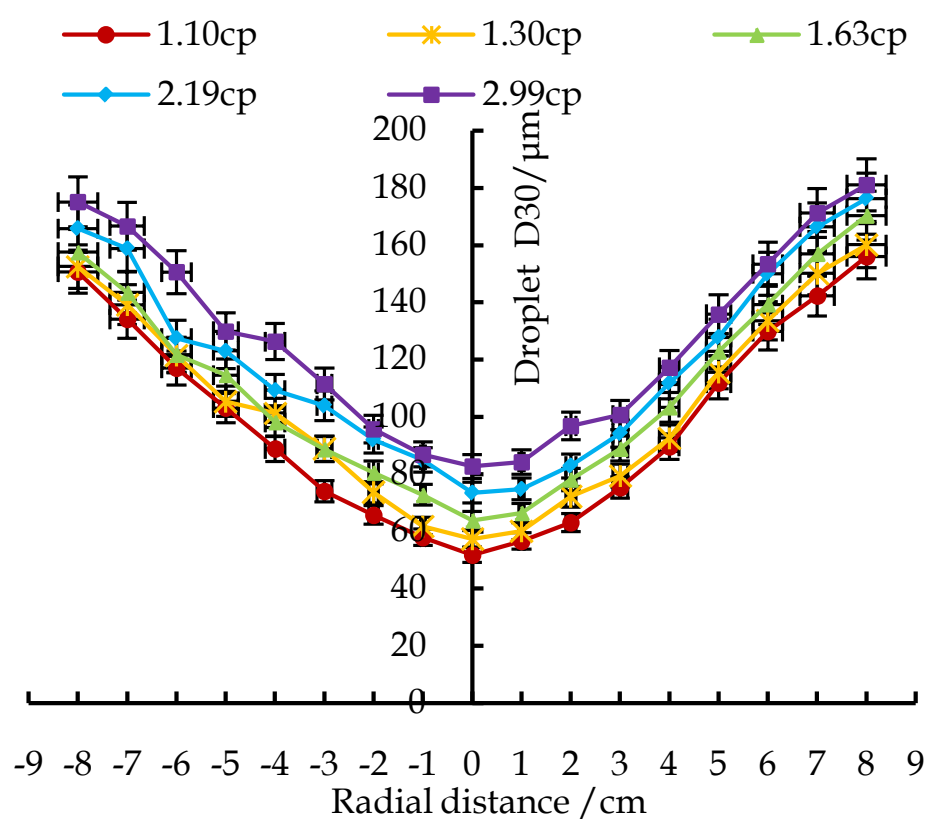

Figure 13. Changes of $D_{30}$ at $z=30 \mathrm{~cm}$.

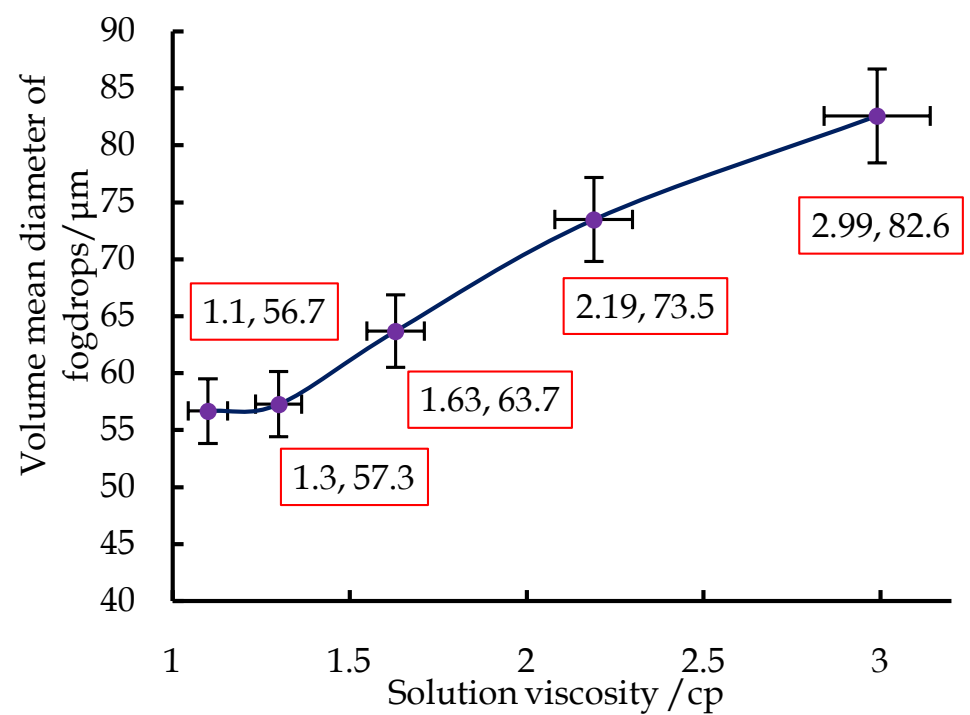

Figure 14. Changes of $D_{30}$ at $Z=30 \mathrm{~cm}$ under different viscosities. 


\subsection{Radical Droplet Speed Distribution}

Moving speeds of droplets at different radial positions under different viscosities at $Z=30 \mathrm{~cm}$ are listed in Table 7.

Radial droplet $D_{30}$ and speed vector maps (for convenience of analysis, the viscosity of spraying solution was $1.63 \mathrm{cp}, z=30 \mathrm{~cm}$ and $y=-8 \mathrm{~cm}-8 \mathrm{~cm}$ ) were drawn with the PDA system to analyse the radial droplet speed distribution (Figure 15). The dot size shows the volume mean diameter of droplets at the position and the arrow length shows the speed. The xoy plane cannot express speed along the $z$-direction. Specifically, the arrow direction shows that the droplet speed is perpendicular to the inward of the xoy plane.

Figure 15 shows that there was a high droplet speed in the middle that gradually decreased as the radial distance increases. The volume mean diameter of the droplet was small in the middle and increased as the radial distance increased. This can be explained as follows. Because of the high droplet speed at axis, droplets are broken completely under high-speed airflow, showing good atomisation

Table 7. Radial droplet speed at $z=30 \mathrm{~cm}(\mathrm{~m} / \mathrm{s})$.

\begin{tabular}{|c|c|c|c|c|c|}
\hline Radial distance/cm & $1.10 \mathrm{cp}$ & $1.30 \mathrm{cp}$ & $1.63 \mathrm{cp}$ & $2.19 \mathrm{cp}$ & $2.99 \mathrm{cp}$ \\
\hline-8 & 3.62 & 3.94 & 4.02 & 5.28 & 5.21 \\
\hline-7 & 3.67 & 3.95 & 4.16 & 4.82 & 4.73 \\
\hline-6 & 3.62 & 4.17 & 4.81 & 4.71 & 4.96 \\
\hline-5 & 4.05 & 5.03 & 5.00 & 5.07 & 5.76 \\
\hline-4 & 4.97 & 4.95 & 6.34 & 6.02 & 6.98 \\
\hline-3 & 6.53 & 6.01 & 7.31 & 7.18 & 7.52 \\
\hline-2 & 8.46 & 8.20 & 8.57 & 9.16 & 8.78 \\
\hline-1 & 10.92 & 10.65 & 10.00 & 10.57 & 9.84 \\
\hline 0 & 12.09 & 11.51 & 11.46 & 10.94 & 10.07 \\
\hline 1 & 11.17 & 10.75 & 10.81 & 10.16 & 9.25 \\
\hline 2 & 8.09 & 8.70 & 8.56 & 9.13 & 8.14 \\
\hline 3 & 6.07 & 7.27 & 7.08 & 8.01 & 7.55 \\
\hline 4 & 4.73 & 5.73 & 5.63 & 6.39 & 6.66 \\
\hline 5 & 4.23 & 4.30 & 4.38 & 5.29 & 6.11 \\
\hline 6 & 3.90 & 4.09 & 4.15 & 5.01 & 5.91 \\
\hline 7 & 4.00 & 4.47 & 4.37 & 4.98 & 5.23 \\
\hline 8 & 4.34 & 4.69 & 4.55 & 4.45 & 4.99 \\
\hline
\end{tabular}

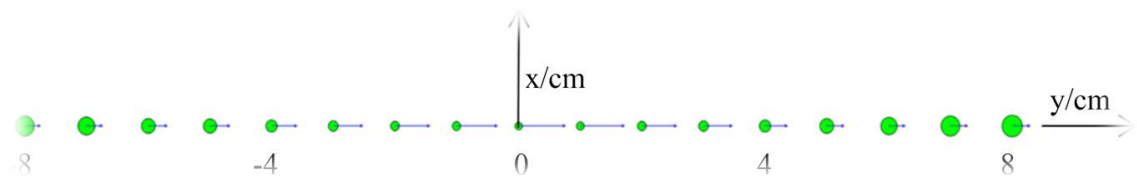

Figure 15. Radial droplet speed vector map. 
effect and small droplet size. Because droplet speed decreases as the radial distance increases, droplets collide and agglomerate into large ones.

\subsection{Kinetic Energy Analysis of Droplets}

To further analyse the effects of viscosity on axial moving characteristics of droplets, test data of droplet speed and droplet size were used. According to the definition of kinetic energy:

$$
E=\frac{1}{2} m v^{2}=\frac{1}{2} \rho \frac{3}{4} \pi r^{3} v^{2}
$$

where, $\rho$ is the spraying solution density, $r$ is half the volume mean diameter of the droplet, and $v$ is the droplet speed.

The kinetic energy of the droplets along the axial direction is shown in Table 8.

The variation curves of the kinetic energy of droplets along the axial direction are shown in Figure 16. The kinetic energy of droplets declined dramatically in the $0 \mathrm{~cm}-6 \mathrm{~cm}$ interval. Because of the atomisation of droplets at the near end

Table 8. Kinetic energy of axial droplets $\left(10^{-9} \mathrm{~J}\right)$.

\begin{tabular}{|c|c|c|c|c|c|}
\hline $\begin{array}{c}\text { Different axial } \\
\text { distance } / \mathrm{cm}\end{array}$ & $1.10 \mathrm{cp}$ & $1.30 \mathrm{cp}$ & $1.63 \mathrm{cp}$ & $2.19 \mathrm{cp}$ & $2.99 \mathrm{cp}$ \\
\hline 0 & $\# \mathrm{~N} / \mathrm{A}$ & $\# \mathrm{~N} / \mathrm{A}$ & $\# \mathrm{~N} / \mathrm{A}$ & $\# \mathrm{~N} / \mathrm{A}$ & $\# \mathrm{~N} / \mathrm{A}$ \\
\hline 2 & 50.8499744 & 19.16194 & 20.38594 & 9.584684 & 4.740067 \\
\hline 4 & 6.74389892 & 5.946501 & 5.070803 & 2.716616 & 1.676254 \\
\hline 6 & 0.43927389 & 0.878568 & 1.861963 & 1.319184 & 2.811490 \\
\hline 8 & 0.69549996 & 0.781383 & 0.751949 & 1.673944 & 3.055864 \\
\hline 10 & 0.82034017 & 0.918688 & 0.983916 & 1.796431 & 4.059404 \\
\hline 12 & 0.94429116 & 1.114586 & 1.164389 & 2.003434 & 4.177923 \\
\hline 14 & 1.04547108 & 1.245835 & 1.191922 & 2.221039 & 4.617580 \\
\hline 16 & 1.16565106 & 1.394226 & 1.415921 & 2.428222 & 3.992973 \\
\hline 18 & 1.31023970 & 1.535756 & 1.602503 & 2.736447 & 4.280702 \\
\hline 20 & 1.40880793 & 1.686800 & 1.843792 & 2.867328 & 4.290333 \\
\hline 22 & 1.59394689 & 1.888162 & 2.131259 & 3.450868 & 4.387770 \\
\hline 24 & 1.68254638 & 2.060087 & 2.167616 & 3.118545 & 4.564219 \\
\hline 26 & 1.83294593 & 2.270008 & 2.467134 & 3.612383 & 4.759648 \\
\hline 28 & 1.94527824 & 2.446932 & 2.674624 & 3.651102 & 4.403056 \\
\hline 30 & 2.14081083 & 2.551674 & 2.906612 & 4.358775 & 4.356921 \\
\hline 32 & 2.24454823 & 2.692019 & 3.152040 & 4.451178 & 4.148331 \\
\hline 34 & 2.33560671 & 2.924093 & 3.362563 & 4.287311 & 4.091374 \\
\hline 36 & 2.49654730 & 3.098775 & 3.598742 & 4.123963 & 4.189788 \\
\hline 38 & 2.70153047 & 3.284950 & 3.780677 & 4.530132 & 4.154724 \\
\hline 40 & 3.19577888 & 3.511340 & 3.951225 & 3.792711 & 3.344166 \\
\hline
\end{tabular}




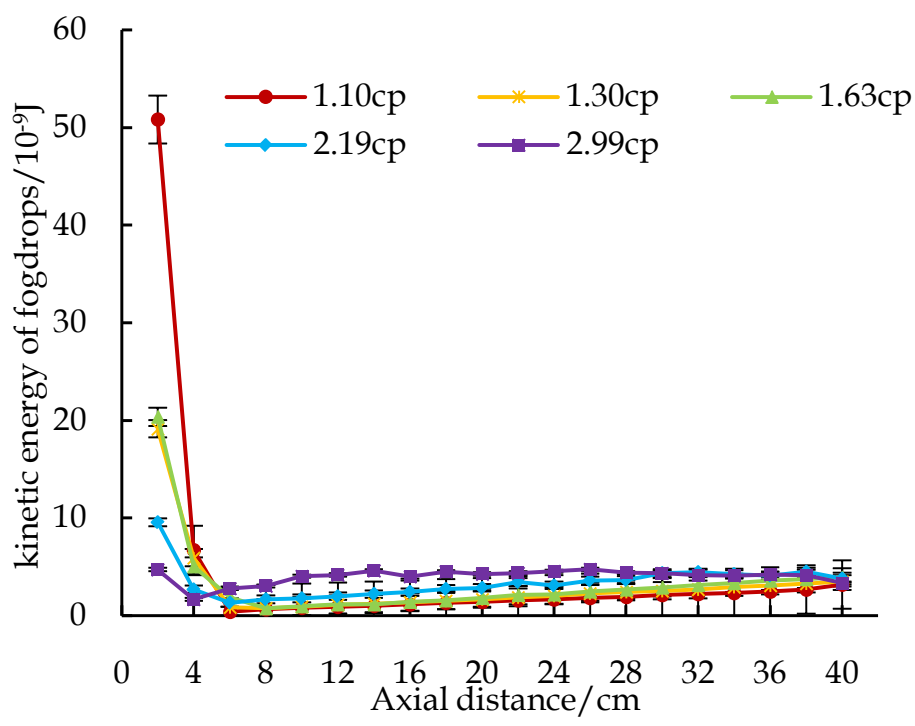

Figure 16. Kinetic energy distribution curve of droplets along the axial direction.

of the nozzle, large droplets broke quickly under the influence of shear stress, accompanied by quick mass attenuation. Hence, the kinetic energy of droplets was decreased. In this interval, the kinetic energy of the droplets with high viscosity was smaller than that of the droplets with low viscosity. This relationship showed that under the same spraying conditions, a spraying solution with higher viscosity required more atomising energy.

In the $z=6 \mathrm{~cm}-40 \mathrm{~cm}$ interval, the kinetic energy of the droplets with different viscosities increased gradually. The measurement results of droplet speed (Table 4) showed that droplet speed in this interval declined gradually, indicating that mass in this interval was a major factor influencing the droplet kinetic energy. Moreover, the droplet mass increased while falling, and the gravitational potential energy of droplets was transformed into kinetic energy, increasing the droplet kinetic energy.

\section{Discussion}

In the experimental environment, temperature can affect the viscosity of the solution to some extent. In viscosity liquid measurements, environmental temperature changes dynamically. Therefore, the environmental temperature was measured many times before each experiment to assure the reliability of the experimental results. A NDJ-8Tdigital rotating viscometer was used to test viscosity. Before each experiment, the test results of the same sample were basically the same, assuring the stability of the results measured.

Droplet size measurement was performed under the hypothesis that droplets were spherical. However, droplets may not be standard spheres. Therefore, the theoretical value of the kinetic energy of droplets was slightly higher than the value measured.

The kinetic energy of the droplet at the target may influence the effective ad- 
hesion of droplets on the target. Relevant causes and results will be further studied in future studies.

\section{Conclusions}

In the present study, variation laws of size, speed and kinetic energy of droplets along perpendicular (axial) and horizontal (radial) directions in the atomisation region under different viscosities were studied using PDA as the test platform. Some conclusions could be drawn:

1) The droplet size from the nozzle was positively related to the viscosity of the spraying solution. As the viscosity increased, the droplet size along the axial direction first increased and then decreased. The high viscosity of the spraying solution resulted in it being more difficult to atomise droplets. The droplet size at the radial boundaries in the atomisation region was higher than the internal droplet size.

2) Droplet speed at the near end of the nozzle decreased at an accelerating speed because of inertial force. The droplet speed increased and droplets were formed as a response to disturbance of the external air resistance.

3) The kinetic energy of droplets dropped quickly in the beginning and then increased slowly along the axial direction. The fast breaking of droplets under the influence of shear stress was the main influencing factor of kinetic energy changes at the near end of the nozzle. However, the droplet mass determined the kinetic energy of droplets at the far end of the nozzle.

4) Adding different concentrations of glycerite significantly affected the droplet size. The spraying solution with different viscosities had different effects. The appropriate mixing ratio should be chosen based on the actual condition of spraying, thus decreasing the drift of pesticide droplets and increasing the penetrability of droplets.

5) According to the test results, droplets in the atomisation region from the solid cone nozzle belonged to mist droplets. In addition, the droplet size outside the fog cone was higher than that inside the fog cone.

\section{Acknowledgements}

This work is supported by the Natural Science Foundation of China (31671591), Guangzhou, Guangdong Provincial Special Fund For Modern Agriculture Industry Technology Innovation Teams (2019KJ108), Special Fund For 2018 Rural Revitalization Strategy Department of Agriculture of Guangdong Provincial (YUE CAI NONG [2018]125), Guangdong Provincial Science and Technology Plan Project (2017A020208049) and Special Fund for Construction of Modern Agriculture Industrial Technology System (CARS-27).

\section{Conflicts of Interest}

The authors declare no conflicts of interest regarding the publication of this paper. 


\section{References}

[1] Mansour, A. and Chigier, N. (1995) Air-Blast Atomization of Non-Newtonian Liquids. Journal of Non-Newtonian Fluid Mechanics, 58, 161-194. https://doi.org/10.1016/0377-0257(95)01356-Z

[2] Doruchowski, G., Świechowski, W., Masny, S., et al. (2017) Low-Drift Nozzles vs. Standard Nozzles for Pesticide Application in the Biological Efficacy Trials of Pesticides in Apple Pest and Disease Control. Science of the Total Environment, 575, 1239-1246. https://doi.org/10.1016/j.scitotenv.2016.09.200

[3] Ferguson, J.C., Hewitt, A.J. and O’Donnell, C.C. (2016) Pressure, Droplet Size Classification, and Nozzle Arrangement Effects on Coverage and Droplet Number Density Using Air-Inclusion Dual Fan Nozzles for Pesticide Applications. Crop Protection, 89, 231-238. https://doi.org/10.1016/j.cropro.2016.07.032

[4] Fan, L.G. (2018) Current Situation, Problems and Countermeasures of Plant Protection Machinery and Pesticide Application Technology in China. Agricultural Development \& Equipments, No. 2, 28-30.

[5] Ren, S.W., Yang, C.M., Chen, G.Y., et al. (2018) Particle Size Distribution Change of Soybean Protein Spray Field. Packaging Engineering, 39, 46-52.

[6] Wu, Y.L., Qi, L.J., Zhang, Y., et al. (2017) Design and Test of Real-Time Monitoring of Droplet Evaporation System Based on Standing Wave and ZigBee. Transaction of the Chinese Society of Agriculture Engineering, 33, 128-135.

[7] Zhang, D.Y., Lan, Y.B., Chen, L.P., et al. (2014) Current Status and Future Trends of Agricultural Aerial Spraying Technology in China. Transactions of the Chinese Society of Agricultural Machinery, 45, 53-59.

[8] Wang, P., Qi, L.J., Li, H., et al. (2013) Influence of Plant Leaf Surface Structures on Droplet Deposition. Transactions of the Chinese Society of Agricultural Machinery, 44, 75-79.

[9] Lan, Y.B., Zhang, H.Y., Wen, S., et al. (2018) Analysis and Experiment on Atomization Characteristics and Spray Deposition of Electrostatic Nozzle. Transactions of the Chinese Society of Agricultural Machinery, 49, 130-139.

[10] Zhang, H.C., Gary, D., Zheng, J.Q., et al. (2012) Wind Tunnel Experiment of Influence on Droplet Size Distribution of Flat Fan Nozzles. Transactions of the Chinese Society of Agricultural Machinery, 43, 53-57.

[11] Zhang, J., Song, J.L., He, X.K., et al. (2011) Droplets Movement Characteristics in Atomization Process of Flat Fan Nozzle. Transactions of the Chinese Society of Agricultural Machinery, 42, 66-69.

[12] Zhang, H.C., Zheng, J.Q., Zhou, H.P., et al. (2017) Droplet Deposition Distribution and Off-Target Drift during Pesticide Spraying Operation. Transactions of the Chinese Society of Agricultural Machinery, 48, 114-122.

[13] Aung, N.Z., Yang, Q., Chen, M., et al. (2014) CFD Analysis of Flow Forces and Energy Loss Characteristics in a Flapper-Nozzle Pilot Valve with Different Null Clearances. Energy Conversion and Management, 83, 284-295.

https://doi.org/10.1016/j.enconman.2014.03.076

[14] De Domenico, F., Rolland, E.O. and Hochgreb, S. (2019) A Generalised Model for Acoustic and Entropic Transfer Function of Nozzles with Losses. Journal of Sound and Vibration, 440, 212-230. https://doi.org/10.1016/j.jsv.2018.09.011

[15] Wen, S., Lan, Y.B., Zhang, J.T., et al. (2016) Analysis and Experiment on Atomization Characteristics of Ultra-Low-Volume Swirl Nozzle for Agricultural Unmanned Aviation Vehicle. Transaction of the Chinese Society of Agriculture Engineering, 
32, 85-93.

[16] Zhang, R.R., Zhang, Z., Xu, G., et al. (2018) Effect of Spray Adjuvant Types and Concentration on Nozzle Atomization. Transaction of the Chinese Society of Agriculture Engineering, 34, 36-43.

[17] Musiu, E.M., Qi, L. and Wu, Y. (2019) Spray Deposition and Distribution on the Targets and Losses to the Ground as Affected by Application Volume Rate, Airflow Rate and Target Position. Crop Protection, 116, 170-180. https://doi.org/10.1016/j.cropro.2018.10.019

[18] Kira, O., Dubowski, Y. and Linker, R. (2018) In-Situ Open Path FTIR Measurements of the Vertical Profile of Spray Drift from Air-Assisted Sprayers. Biosystems Engineering, 169, 32-41. https://doi.org/10.1016/j.biosystemseng.2018.01.010

[19] Zhu, C.Q. and Wang, R.R. (2018) Study on Atomization Simulation of Smoke Machine Nozzle. Equipment Manufacturing Technology, No. 7, 51-54.

[20] Wang, X.F. (2015) New Thoughts on the Development of Plant Protection Machinery in China. Modernizing Agriculture, No. 8, 1-3.

[21] Mohan, A., Chidambaram, P.K., Suryan, A., et al. (2019) Energy Efficiency Analysis of Wet Compression Systems through Thermo-Fluid Dynamic Considerations. Journal of Cleaner Production, 214, 132-144. https://doi.org/10.1016/j.jclepro.2018.12.285

[22] Raoult, F., Lacour, S., Carissimo, B., et al. (2019) CFD Water Spray Model Development and Physical Parameter Study on the Evaporative Cooling. Applied Thermal Engineering, 149, 960-974.

https://doi.org/10.1016/j.applthermaleng.2018.12.063

[23] Qi, L.J. and Fu, Z.T. (1999) Experimental Study on Spray Deposition Uniformity. Transaction of the Chinese Society of Agriculture Engineering, No. 2, 113-117.

[24] Shin, P., Sung, J. and Lee, M.H. (2011) Control of Droplet Formation for Low Viscosity Fluid by Double Waveforms Applied to a Piezoelectric Inkjet Nozzle. Microelectronics Reliability, 51, 797-804. https://doi.org/10.1016/j.microrel.2010.11.017

[25] Kumar, M., Sahoo, R.K. and Behera, S.K. (2019) Design and Numerical Investigation to Visualize the Fluid Flow and Thermal Characteristics of Non-Axisymmetric Convergent Nozzle. Engineering Science and Technology, an International Journal, 22, 294-312. https://doi.org/10.1016/j.jestch.2018.10.006

[26] Ejim, C.E., Rahman, M.A., Amirfazli, A., et al. (2010) Effects of Liquid Viscosity and Surface Tension on Atomization in Two-Phase, Gas/Liquid Fluid Coker Nozzles. Fuel, 89, 1872-1882. https://doi.org/10.1016/j.fuel.2010.03.005

[27] Nska, S.R.Z., Broniarz-Press, L., Nski, J.R.Z., et al. (2013) Extensional Viscosity of Ow Emulsion Stabilized by Polysaccharides. Food Hydrocolloids, 32, 130-142. https://doi.org/10.1016/j.foodhyd.2012.12.018

[28] Li, Z.X., Guo, Z.H., Che, J.L, et al. (2014) Flow Field and Spray of a High Shear Air-Blast Nozzle. Journal of Aerospace Power, 29, 2704-2709.

[29] Ye, L.M., Lv, T.F., Cui, W.S., et al. (1994) The Distributing Homogeneity of Quantity of Fog Analysis of Boom Type Atomizing Machine in Allovt Atomizing. Journal of Jiamusi University (Natural Science Edition), No. 2, 110-113.

[30] Lee, C.H. and Reitz, R.D. (2000) An Experimental Study of the Effect of Gas Density on the Distortion and Breakup Mechanism of Drops in High Speed Gas Stream. International Journal of Multiphase Flow, 26, 229-244.

https://doi.org/10.1016/S0301-9322(99)00020-8 